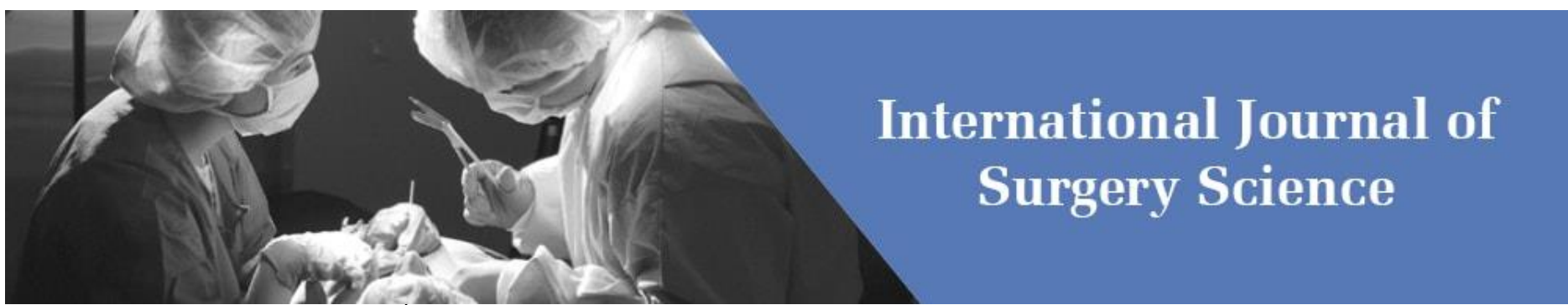

E-ISSN: 2616-3470

P-ISSN: 2616-3462

(C) Surgery Science

www.surgeryscience.com

$2019 ; 3(4): 377-380$

Received: 04-08-2019

Accepted: 06-09-2019

Dr. Abhishek Vats

M.S., General- Surgery, Assistant-

Professor, S.G.T. Medical College

Hospital and Research Center,

Chandu Budhera, Gurugram,

Haryana, India

Dr. Karan Vats

M.S., General- Surgery, Senior-

Resident, Deen Dayal Upadhyay

Hospital, Delhi, India

Dr. Paras Kumar Gupta

M.S., General- Surgery, Senior-

Resident, S.G.T. Medical College

Hospital and Research Center,

Chandu Budhera, Gurugram,

Haryana, India

Dr. Pawan Tiwari

M.S., General- Surgery, Professor,

S.G.T. Medical College Hospital and Research Center, Chandu

Budhera, Gurugram Haryana,

India

\section{Study of relative frequency, causes and clinical presentation of pathological swellings of liver}

\author{
Dr. Abhishek Vats, Dr. Karan Vats, Dr. Paras Kumar Gupta and \\ Dr. Pawan Tiwari
}

DOI: https://doi.org/10.33545/surgery.2019.v3.i4g.270

\begin{abstract}
Introduction: Swelling in the epigastrium is caused by those organs anatomically present in the epigastric region and sometimes by other organs situated in other parts of body in the other regions. This study was done to know the clinical presentation of swellings arising from liver among the epigastric swellings.

Methods: Fifty-two cases with a pathological swelling in the epigastrium, who were admitted to tertiary care center, were randomly selected and studied during their stay in the hospital. The patients of age more than 12 years were included. Relevant investigations were done and the diagnosis confirmed.

Results: There were total 25 cases with liver swellings in Liver. Liver abscess was $23 \%$, liver cyst $5.7 \%$, hydatid cyst of liver and hepatocellular carcinoma 3.84\% each and hemangioma about $1.96 \%$ of the total no of cases. Nausea $(61.53 \%)$, pain $(55.76 \%)$, vomiting (51.95\%), weight loss $(40.38 \%)$, fever (34.61\%), anorexia $(32.69 \%)$ were the presenting symptoms.

Conclusion: Liver abscess was the most common swelling in the liver. The least common swelling was hemangioma (1.96\%). Most common symptom was nausea, followed by pain, weight loss. The least common symptom was gastrointestinal bleeding.
\end{abstract}

Keywords: Epigastrium, liver, liver abscess, nausea, pain, vomiting

\section{Introduction}

Liver abscess descriptions dates back to Hippocrates in approximately 4000 B.C. John bright provided the first description of the disease in modern medicine in 1836 while giving discourse on jaundice. In 1938, Ochsner and associates provided a landmark collective review of pyogenic liver abscesses in the preantibiotic era ${ }^{[1]}$. In 1856, Bristowe first reported a case of nonparasitic cystic disease of the liver and emphasized the association with polycystic renal disease. In the same year, Michel recorded the first solitary, nonparasitic cyst. Hadad and associates reviewed almost 900 cases of the cysts ${ }^{[2]}$ Frerich, 1861 is credited with the first description of hemangiomas in medical literature ${ }^{[3]}$. Rokitansky, in 1855, first distinguished between primary and metastatic hepatic tumors. The first hepatic resection for metastatic diseases were reported by Garre, in 1888, and by Keen in 1899, and Wangensteen performed a total right lobectomy in 1949 for a metastatsis from gastric cancer. In 1963, Woodington and Waugh first demonstrated that resection of hepatic colorectal metastases resulted in improved survival ${ }^{[4]}$. The abdomen as a whole and epigastrium in particular, provokes and challenges the abilities of the surgeon in eliciting the clinical findings and their interpretation. If we consider the number of organs pathologically involved in each region, epigastrium has a significant number of organs involved. In this study, an effort has been made to study swellings from liver, which forms a significant percentage of the pathology of the swellings present in the epigastrium. The left lobe of the liver is predominantly present in the epigastrium, but when the right lobe is also enlarged there is significant part of the liver palpable in the epigastrium. Here, an effort to study the space occupying lesions of the left lobe of the liver has been made.

\section{Methodology}

The material of study was obtained from the patients admitted during the period of April 2004 to March 2006 in a tertiary care hospital. 52 cases of epigastric swellings, were selected randomly, and studied during their stay in the hospital. Each of these cases was studied according to the case proforma, taking a detailed history and the cases were examined thoroughly.

\section{Dr. Abhishek Vats}

M.S., General- Surgery, AssistantProfessor, S.G.T. Medical College

Hospital and Research Center,

Chandu Budhera, Gurugram,

Haryana, India 
The presence of the swelling in the epigastrium was confirmed by ultrasound scan and/or CT scan. The other relevant investigations were done to arrive at the diagnosis.

\section{Results}

Table 1: Epigastric swellings, relative frequency of the organs involved

\begin{tabular}{|c|c|c|}
\hline Swellings & Number of cases & Percentage \\
\hline Swelling from the liver (left lobe) & $25(4)$ & 48.07 \\
\hline
\end{tabular}

Out of the 52 cases selected, 29 were swelling from the liver (left lobe),

Table 2: Epigastric swelling, relative frequency of symptoms, as a whole

\begin{tabular}{|c|c|c|}
\hline Symptoms & No of cases & Percentage \\
\hline Pain & 29 & 55.76 \\
\hline Nausea & 32 & 61.53 \\
\hline Vomiting & 27 & 51.9 \\
\hline Fever & 18 & 34.61 \\
\hline GIT bleeding & 5 & 9.61 \\
\hline Anorexia & 17 & 32.69 \\
\hline Weight loss & 21 & 40.38 \\
\hline Jaundice & 15 & 28.84 \\
\hline
\end{tabular}

All the cases when considered together, nausea was the most common symptom $(61.53 \%)$, followed by pain $(55.76 \%)$, vomiting $(51.9 \%)$, weight loss $(40.38 \%)$, fever $(34.61 \%)$, anorexia (32.69\%), jaundice (28.84\%), GIT bleed was the least common symptom about $9.61 \%$ (table 2 ).

Table 3: Epigastric swelling, age wise distribution

\begin{tabular}{|c|c|}
\hline Age (years) & Number of cases \\
\hline $14-30$ & 4 \\
\hline $31-50$ & 25 \\
\hline $51-70$ & 21 \\
\hline$\geq 71$ & 2 \\
\hline
\end{tabular}

The age of; distribution of epigastric swellings has been described in table 3 . The most number of patients about 25 cases are in the age group of 31-50 years. This was followed by age group of 51-70 which accounted for 21 cases, then the age group of 14-30 which numbered around 4 cases, and the least number of cases were above 71 about 2 cases.

Table 4: Epigastric swelling, sex wise distribution

\begin{tabular}{|c|c|}
\hline Sex & Number of cases \\
\hline Male & 38 \\
\hline Female & 14 \\
\hline
\end{tabular}

Among the 52 cases, 14 were female patients and 38 were male patients. The present study shows that, there were, more number of male cases, about 2.71 males for every female patient (table $4)$.

\section{Liver Swellings}

Table 5: Liver swellings of left lobe, relative frequency of the cause

\begin{tabular}{|c|c|c|}
\hline Swellings & Number of cases & Percentage \\
\hline Liver abscess & 12 & 41.3 \\
\hline Secondaries liver & $9(4)$ & 31.03 \\
\hline Liver cyst & 3 & 10.34 \\
\hline Hydatid cyst of liver & 2 & 6.89 \\
\hline Hepatocellular carcinoma & 2 & 6.89 \\
\hline Haemangioma of liver & 1 & 3.44 \\
\hline
\end{tabular}

Among the 29 cases of liver swelling of left lobe, 12 cases were liver abscess, 9 cases were secondaries of liver, 3 cases were liver cyst, 2 cases were hydatid cyst of liver, 2 cases were hepatocellular carcinoma and 1 case was haemangioma of the liver (table 5).

Table 6: Liver abscess, relative frequency of amoebic and pyogenic liver abscess

\begin{tabular}{|c|c|c|}
\hline Liver abscess & Number of cases & Percentage \\
\hline Amoebic liver abscess & 7 & 58.33 \\
\hline Pyogenic liver abscess & 5 & 41.66 \\
\hline
\end{tabular}

Among the 12 cases, 7 cases were of amoebic liver abscess forming about $58 \%$, and 5 cases of pyogenic liver abscess, which formed about $42 \%$ (table 6).

Table 7: Liver abscess, sex distribution

\begin{tabular}{|c|c|c|}
\hline Sex & Number of cases & Percentage \\
\hline Males & 10 & 83.33 \\
\hline Females & 2 & 12.66 \\
\hline
\end{tabular}

Liver abscess, considering both pyogenic and amoebic, males were more affected than females. The patients in this study were between the ages of 26-43 years (table 7).

Table 8: Amoebic liver abscess, relative frequency of the symptoms

\begin{tabular}{|c|c|c|}
\hline Symptoms & Number of cases & Percentage \\
\hline Pain & 7 & 100 \\
\hline Fever & 6 & 85.7 \\
\hline Nausea & 5 & 71.4 \\
\hline Vomiting & 5 & 71.4 \\
\hline Anorexia & 3 & 42.8 \\
\hline Weight loss & 2 & 28.57 \\
\hline Malaise & 1 & 14.28 \\
\hline Jaundice & 1 & 14.28 \\
\hline
\end{tabular}

All the cases presented with pain, the next common symptom was fever about $86 \%$. Other symptoms were nausea, vomiting, each making $71 \%$ of the symptoms, anorexia about $43 \%$, weight loss about $28.5 \%$, malaise and jaundice $14 \%$ (table 8 ). All the patients in the present study were alcoholic. Hepatomegaly was present in all cases. Serum bilirubin was increased (around 5 $\mathrm{mgm} / \mathrm{dl}$ ) only in 1 case. Serum alkaline phosphatase was increased in 3 cases. It was not done in 4 cases. All the cases had single left lobe liver abscess as shown by ultrasound scan, the volume of the abscess cavity was between $115 \mathrm{ml}$ to $312 \mathrm{ml}$. On aspiration there was anchovy sauce like pus in these cases and it was sterile on culture. The patients in the study with pyogenic liver abscess, were in the age group of 48-70 years, about 4 cases more than 50 years $(80 \%)$. There were 2 female cases and 3 male cases, a ratio of 1.5 males for every female.

Table 9: Pyogenic liver abscess, relative frequency of the symptoms

\begin{tabular}{|c|c|c|}
\hline Symptoms & Number of cases & Percentage \\
\hline Fever & 4 & 80 \\
\hline Weight loss & 3 & 60 \\
\hline Pain & 3 & 60 \\
\hline Nausea & 3 & 60 \\
\hline Vomiting & 3 & 60 \\
\hline Malaise & 3 & 60 \\
\hline Chills & 2 & 40 \\
\hline Anorexia & 2 & 40 \\
\hline Jaundice & 2 & 40 \\
\hline
\end{tabular}


Fever was the most common symptom present in about $80 \%$ cases. The other symptoms were weight loss, pain, nausea, vomiting, malaise each present in about $60 \%$, and chills anorexia, jaundice were present in about $40 \%$ of the cases of pyogenic liver abscess (table 9). There were multiple abscesses in 2 cases and rest of 3 cases it was a single left lobe lesion, the lesions were measuring between $140 \mathrm{ml}$ to $656 \mathrm{ml}$. Serum bilirubin was raised in 2 of the 5 cases, and alkaline phosphatase was raised in 4 cases and it was not done in 1 case. There was marginal increase of SGOT in 3 cases and normal in 1 case and not done in 1 case. The culture of the pus yielded a mixed infection. There were 9 cases with liver secondaries. Among them, 8 were male, and 1 was female (table 10).

Table 10: Liver secondaries, sex distribution

\begin{tabular}{|c|c|}
\hline Sex & Number of cases \\
\hline Male & 8 \\
\hline Female & 1 \\
\hline
\end{tabular}

Table 11: Liver secondaries, etiology

\begin{tabular}{|c|c|c|}
\hline Liver secondaries & Number of cases & Percentage \\
\hline Carcinoma stomach & 1 & 11.1 \\
\hline Carcinoma colon and rectum & 3 & 33.3 \\
\hline Carcinoma pancreas & 3 & 33.3 \\
\hline cholangiocarcinoma & 1 & 11.1 \\
\hline Carcinoma lung & 1 & 11.1 \\
\hline
\end{tabular}

In the present study of liver metastases, primary is commonly from gastrointestinal tract (carcinoma colon, carcinoma pancreas, carcinoma rectum, carcinoma stomach and cholangiocarcinoma.). The other case is a carcinoma lung with liver secondaries (table 11).

Table 12: liver secondaries, relative frequency of the symptoms

\begin{tabular}{|c|c|c|}
\hline Symptoms & Number of cases & Percentage \\
\hline Weight loss & 7 & 77.7 \\
\hline Jaundice & 3 & 33.3 \\
\hline Vomiting & 2 & 22.2 \\
\hline Anorexia & 6 & 64.4 \\
\hline Nausea & 3 & 33.3 \\
\hline Ascites & 2 & 22.2 \\
\hline Hepatomegaly & 6 & 64.4 \\
\hline
\end{tabular}

In this study, most common symptoms were weight loss and anorexia which was about $78 \%$ and $64 \%$ respectively. Jaundice and nausea were present in $33 \%$ of cases, vomiting in $22 \%$ of cases, ascites in $22 \%$ of cases (table 12). Serum bilirubin was increased in 4 cases. Serum alkaline phosphatase in 1 case and serum glutamic pyruvic transaminase and serum glutamic oxaloacetic transaminase were increased in 2 cases. There were two cases of hepatocellular carcinoma in this study, both were males, and of age 40 years and 50 years. Both had jaundice, loss of weight, vague epigastric pain, nausea. One case had GI bleed, ascitis and on ultrasound scan there were features suggestive of IVC thrombosis. There was increased bilirubin, increased SGPT and SGOT. There was one case of hepatic cyst along with polycystic kidney disease. The patient was asymptomatic with regards to the liver cyst. There was hepatomegaly and renal enlargement on either side, with hypertension. It was detected on ultrasound scan of abdomen which showed multiple cysts of the liver and kidneys. The second case of liver cyst was a simple cyst of the liver, this was also asymptomatic. The patient presented with symptoms of left ureteric colic and there was hepatomegaly. There was one case of traumatic liver cyst. This patient presented with pain in the epigastrium dull aching type. He gave history of trauma about one month back and on examination, there was enlargement of liver. On ultrasound scan of the abdomen, there was a traumatic cyst in the liver which was in the left lobe and subcapsular in position. There was one case of haemangioma of liver which was asymptomatic. The patient presented with symptoms of appendicitis, there was enlargement of liver. The hemangioma was diagnosed on ultrasound scan of the abdomen. There were 2 cases of hydatid cyst of liver, one was male (aged 40) and the other female (aged 30).

Table 13: Hydatid cyst of liver, relative frequency of the symptoms

\begin{tabular}{|c|c|c|}
\hline Symptoms & Number of cases & Percentage \\
\hline Pain & 2 & 100 \\
\hline Fever & - & - \\
\hline Vomiting & 2 & 100 \\
\hline Anorexia & - & - \\
\hline Weight loss & - & - \\
\hline Jaundice & - & - \\
\hline
\end{tabular}

Both the cases presented with pain and vomiting, and there was no other symptom associated with it (table 13). There was hepatomegaly in both the cases. On ultrasound scan, one case showed multiple hydatid cysts in both the lobes of the liver, eosinophilia and elevated SGPT and another case showed single left lobe hydatid cyst of liver with normal blood investigations.

\section{Discussion}

The findings of our study were compared with that of Maingot et al. The percentage of occurrence of symptoms are similar in both the studies. Weight loss is higher in the Maingot's study, all the cases in our study had hepatomegaly whereas about $85 \%$ of patients had hepatomegaly according to Maingot's study [5] (table 14). Increased bilirubin was found in $10 \%$ as given by Maingot's. In the present study, only one case out of the 7 had bilirubin more than $2 \mathrm{gm} / \mathrm{dl}$ which is about $14.28 \%$. In our study the cases were aged in the range of 48-70 years, most of the cases in the sixth decade. This is similar to Schwartz ${ }^{[6]}$ who also reported peak incidence in the $6^{\text {th }}$ and $7^{\text {th }}$ decade.

Table 14: Comparison table, of symptoms of amoebic liver abscess

\begin{tabular}{|c|c|c|}
\hline Symptoms & Maingot's study & Present study \\
\hline Pain & $90 \%$ & $100 \%$ \\
\hline Fever & $87 \%$ & $85.7 \%$ \\
\hline Nausea and vomiting & $85 \%$ & $71 \%$ \\
\hline Anorexia & $50 \%$ & $42.8 \%$ \\
\hline Weight loss & $45 \%$ & $28.57 \%$ \\
\hline Malaise & $25 \%$ & $14 \%$ \\
\hline
\end{tabular}

Rise in alkaline phosphatase was the most common derangement of LFT according to Maingot's study which was about $87 \%$. This is similar to our study where ALP is raised in 4 out of 5 cases, that is, about $80 \%$ of the cases. The symptomatology in the 2 cases of hepatocellular carcinoma in this study, were the same as that by Okukak study ${ }^{[7]}$ who gave the same signs and symptoms. It was more common in the age group of 30-50 years $^{8}$. In our study, most common primary tumour of liver metastases was from colorectal cancer and pancreas. This is similar to that given in Maingot's study ${ }^{[9]}$. In our study, most common symptoms were weight loss and anorexia while hepatomegaly was the commonest sign, which is similar to $\mathrm{S}$ Das ${ }^{[10]}$ (Table 15). 
Table 15: Comparison table of symptoms of pyogenic liver abscess

\begin{tabular}{|c|c|c|}
\hline Symptoms & S. Das study & Present study \\
\hline Fever & $83 \%$ & $80 \%$ \\
\hline Weight loss & $60 \%$ & $60 \%$ \\
\hline Pain & $55 \%$ & $60 \%$ \\
\hline Nausea and vomiting & $50 \%$ & $60 \%$ \\
\hline Malaise & $50 \%$ & $60 \%$ \\
\hline Chills & $37 \%$ & $40 \%$ \\
\hline Anorexia & $34 \%$ & $40 \%$ \\
\hline
\end{tabular}

\section{Conclusion}

Liver is the most common organ involved in the pathological swellings of the epigastrium. Liver abscess is the most common cause of the swellings of the epigastrium. These are more common in the age group of 31-50. Males are commonly affected. The swelling patients have most commonly has nausea, pain, vomiting. Liver abscess was the most common pathological swelling in the liver. The patients with amoebic liver abscess complaints of pain, fever, nausea, vomiting, rarely jaundice may be seen. The abscesses in the left lobe were smaller than those in the right lobe, before complications occured. Pyogenic abscess affected males slightly higher than females. They had fever, pain, weight loss, nausea, vomiting as the complaints. Jaundice was more common in pyogenic liver abscess than amoebic liver abscess. The liver abscess was associated with increase in alkaline phosphatase. The liver secondaries were commonly encountered with the primaries from the gastrointestinal tract. The symptoms include weight loss, anorexia, jaundice, nausea. Hepatocellular carcinoma had sex preference, presented with pain, weight loss, jaundice, nausea. Hepatic cysts were asymptomatic as well as hemangioma which are an incidental finding. Hydatid cyst of the liver seems to affected both males and females equally, had pain and vomiting on presentation.

\section{References}

1. Stephen A Barnu, Keith D Lillemore. Liver abscess and Hydatid cyst disease, section 1 1, In: Maingot`s abdominal operations, Micheal J. Zinner, Seymour I. Schwartz, Harold Ellis (eds) $10^{\text {th }}$ edition, Stamford: Appleton and Lange. 1997; 51(2):1513.

2. Seymour I Schwartz. Cysts and benign tumors, section11, chapter In: Maingots abdominal operations, Micheal J. Zinner, Seymour I. Schwartz, Harold Ellis (eds) $10^{\text {th }}$ edition, Stamford: Appleton and Lange. 1997; 52(2):1547.

3. Seymaur I Schwartz. Cysts and benign tumours, section11 In: Maingots abdominal operations, Micheal J. Zinner, Seymour I. Schwartz, Harold Ellis (eds) $10^{\text {th }}$ edition, Stamford: Appleton and Lange. 1997; 52(2):1551.

4. Peter W Soballe, John Mdaly. Hepatic metastases, section11, In: Maingots abdominal operations, Micheal J. Zinner, Seymour I. Schwartz, Harold Ellis (eds) $10^{\text {th }}$ edition, Stamford: Appleton and Lange. 1997; 54(2):1591.

5. Stephen A Barnu, Keith D Lillemore. Liver abscess and Hydatid cyst disease, section11, In: Maingot's abdominal operations, Micheal J. Zinner, Seymour I. Schwartz, Harold Ellis (eds) $10^{\text {th }}$ edition, Stamford: Appleton and Lange; 1997; 51(2):1529.

6. Seymour I Schwartz, Liver. Chapter 28, In: Principles of Surgery, Schwartz, Shries, Spencer, Daly, Fischer, Galloway (eds), $7^{\text {th }}$ edition: New York: McGraw-Hill Company 1999; 2:1399.

7. Okuda K, Obata H, Nakayhuma Y et al. Prognosis of primary hepatocellular carcinoma. Hepatology 1984; 4:35.
8. Daniel R. Jacobson, Hepatocellular carcinoma, emedicine, (cited 2006feb 8); 2004; 2(12): (12screens). Available from: URL:http://www.emedicine.com.

9. Peter W Soballe, John Mdaly. Hepatic metastases, section11, chapter 54, vol 2. In: Maingots abdominal operations, Micheal J. Zinner, Seymour I. Schwartz, Harold Ellis (eds) $10^{\text {th }}$ edition, Stamford: Appleton and Lange; 1997, 1591.

10. Das S. The liver and portal hypertension. Chapter 45, In: A concise textbook of surgery, S. Das (ed.), $3^{\text {rd }}$ edition Calcutta: Das, 2002, 878. 